Marketing in Asia Group

\title{
Comparing Work-Related Values of US, Canadian, Chinese, Iranian, and Moroccan Business Students: Multi-Theory Perspective
}

\author{
Nicholas Hamelin \\ Department of Marketing, SP Jain School of Global Management, Australia \\ Niloofar Nasiri \\ Department of Management and Accounting, University of Tehran, Iran \\ Shahamak Rezaei \\ Department of Social Sciences and Business, Roskilde University, Denmark \\ Yasmina El Haddou-Yousefi \\ Department of Business Administration, Al Akhawayn University, Morocco
}

\begin{abstract}
This study aims to investigate preferred management styles and attitudes of business students with a focus on Theory X/Y, Personal Values, Conflict Management Styles, Cultural Context and Machiavellianism. The study also provides a comparison across five countries, namely Morocco, the United States, China, Canada, and Iran. Data was collected using a survey. The sample includes 1,497 university students from the United States, Canada, China, Morocco, and Iran. The results show that participants from all five countries scored high in Theory Y, while Moroccan participants reported the highest Machiavellianism scores among the five countries. Family, Professional, and Spiritual values received the highest scores among participants and their communication style is more likely to be considered "Low Context". Participants were more likely to choose Accommodating or Competition when faced with conflict and were less likely to choose Compromise; however, Accommodating was more prevalent in Eastern cultures (Iran, China, and Morocco) and Competition in Western cultures (U.S. and Canada).This study provides insights on the management of a mixed, international corporate culture which is particularly important for the internationality of the current business climate and will also promote the future youth employment toward workplace multiculturalism.
\end{abstract}

Keywords: Work-Related Value, Cultural Context, Theory X/Y, Machiavellianism, Conflict Management, Student Self-Assessment Research Project (SSARP) 


\section{Introduction}

In the past few decades, as a result of globalization and the rapid development of economics, multinational corporations (MNCs) are more and more prevalent and the differences in the cultural and management modes of multinational enterprises may create conflicts in communication and cooperation (Ike Nnia, 2015). There is a current debate concerning the degree to which values are converging due to globalization (Andreassi et al., 2014). Although Schwarts and Bardi (2001) found that there is a significant degree of similarity regarding value hierarchies, examining ones' national cultural values is not sufficient as people are influenced by varying cultures and their identity (Sackmann and Philips, 2004). The explosion of businesses, establishing multinational companies and international joint ventures increasingly acknowledging the importance of cultural and work value influence on the relationship between human resources and the companies has recognized that the key to their success lies in investing in human capital (Brocaglia, 2011).

Human capital is now considered to be the most valuable asset a company might acquire, which explains why companies are increasingly investing in education, training, and development, while treating human resource expenditures as an investment, rather than an expense (Weatherly, 2003). The challenge for companies dealing with a multicultural workforce goes beyond education, training, and development; it encompasses acquiring knowledge, understanding the various cultures present, and even adapting work practices (Ike Nnia, 2015). Education is the starting point for developing human capital, where each and every student is considered to be potential human capital. Thus, in order to shape their human resources vision, companies are now eager to know about students and their workplace expectations. Given the importance of students in shaping the future of companies, we have seen an increased emphasis on researching and assessing student values and attitudes towards work. One of those studies is the Student Self-Assessment Research Project (SSARP), the multicultural study that began in 2005 by Professor Bowlby at King's University College (The University of Western Ontario, 2010).

SSARP and other such studies offer significant added value when it comes to assessing corporate culture, workplace practices, and the characteristics of future employees. More specifically, one of the objectives of this study is to enable employers to know more about the future human resource in terms of the management style they prefer (i.e. Theory X or Y), personal values, the level of Machiavellianism, preferred conflict management styles, and the cultural context of their communication style. Another objective is to compare each of the above five characteristics crossculturally, thus offering insight into successful management practices. The empirical basis for our study is data collected from university and college business students from both public and private schools. In our study, we compare the working values of American, Canadian, Chinese, Iranian, and Moroccan students to isolate cultural differences. The study is limited to sophomore and junior students enrolled in a business, economics, or a professional program.

The paper is structured as follows: 1) the theoretical concept and research background, include the existing studies overview from the angle of the aim of this paper; 2) the second section describes the research method and the sample characteristics; 3) the next part reports the empirical findings from the research 
comparing work values dimensions, Theory $\mathrm{X} / \mathrm{Y}$, high and low cultural context, conflict management style, and Machiavellianism between students; 4) the concluding section deals with discussion of the study and the suggestions for future research are put forward as well.

\section{Theoretical Concepts and Research Background}

Every country exhibits distinct cultural traits that influence its people. People coming from similar surroundings normally tend to follow "a pattern of shared attitudes, beliefs, categorizations, self-definitions, norms, role definitions, and values that are organized around a theme that can be identified among those who speak a particular language, during a specific historic period, and in a definable geographic region (Triandis, 1996, p. 407). Triandis referred to this characteristic as a "cultural syndrome." Flowers et al. (1975) defined two main categories of values: the "outerdirected" and the "inner-directed." The outer-directed values include tribalistic (submissive to authority or tradition), conformist (sacrificial, has a low tolerance for ambiguity), and sociocentric (high need for affiliation and little concern for wealth), whereas inner-directed values include egocentric (aggressive, selfish, and impulsive), manipulative (materialistic, expressive, and self-calculating to achieve an end), and existential (a high tolerance for ambiguity and for those who have different values; usually expresses self but not at the expense of others). After a comparison of results with the Arab sample used in Ali (1988) and the U.S. sample used in Hughes and Flowers (1978), Ali and Wahabi (1995) found that the inner-directed values were more prevalent among Moroccan and American managers, while outer-directed values were more dominant among the Arab states.

Wolburg and Pokrywczynski (2001, p. 40) argue that "traits and other psychological variables have long been of interest to marketers for their role in consumer behavior, that is, the psychological side of marketing." Such variables are significantly influenced by cultural background, environment, and personal values. The understanding of cultural differences will help individuals to work more efficiently (Husted and Allen, 2008) and let the companies identify market entry opportunities and employee performance approach (Shenkar, 2001). These factors further play a role in the work-related values and attitudes of students and their view of job opportunities. The leadership style can assist students in overcoming communication barriers at work during initial stages and inspire them to more collaboration which builds stronger ties and knowledge sharing behavior (Bradshaw et al., 2015). The multiple concepts and theories addressed in this study will reveal that such cultural syndromes do exist in each comparison country.

\section{McGregor's Theory X/Y}

Douglas McGregor developed two contrasting theories that explained managers' beliefs about their attitudes toward workforce motivation. Theory $\mathrm{X}$ managers emphasize the chain of command, reward or punishment, motivational techniques, and close supervision of subordinates who are assumed to be interested in physical needs. Theory Y managers believe that employees are committed to working; they inherently prefer to work rather than not to work (McGregor, 1960). 
For McGregor, Theory Y managers are more likely to develop a climate of trust with employees through more open communication, they create a comfortable environment for employees to use their abilities. They believe that the satisfaction of doing a good job is a strong motivator. The implication of Theory $\mathrm{X}$ is that if organizational goals are to be met, managers must structure the work and energize the employee. This therefore would lead the manager to apply the authoritarian style of management, in which the employees are not self-control and self-direction in accomplishing objectives to which they have to be committed (Papa et al., 2008).

According to Urban (2003), Theory X represents an old-fashioned and authoritative management style under which employees are expected to do as ordered without being given personal responsibility. In contrast, Theory $\mathrm{Y}$ espouses a more modern style of management where employees are encouraged to be autonomous, creative, and responsible. Lerner (2011), explains that McGregor's Theory X/Y, in general, and perhaps more profoundly, was a better understanding of how people were thinking and behaving within those constructs. He provided a powerful framework for organization sets of beliefs and behaviors to be available for beneficial use by people and organization.

\section{Hofstede's Culture Dimension}

Culture is always a collective phenomenon of mind that distinguishes the members of groups or categories of people from others (Hofstede, 2010). According to Hofstede (2010), power distance relates to the level of acceptance of the unequal distribution of power and its normalization. Cultures that endorse low power distance expect and accept power relations are decentralized, consultative or democratic; in contrast, high power distance cultures represent high power centralization. They are more autocratic and paternalistic. Research by Clugston et al. (2000) has indicated that people from the East (e.g. Japan, India, and China) show more power distribution inequality in comparison to West (e.g., United States, Canada, and Australia). According to Albaum et al. (2010), in a research concerning the relationship between management style and cultural values of decision makers, Chinese managers scored high on power distance. In another study, Iranian manager reported fairly high levels of power distance (Dastmalchian et al., 2001) while several other studies have documented a high power distance in Morocco (Nouiga, 2003; Hmaida, 2010).

The second dimension is individualism-collectivism, which expresses the level of integration of individuals within groups. In individualistic societies, an individual's primary concern is for their own interests and their immediate family, but in a collectivistic society, people are defined by their group actions rather their own actions. In individualistic cultures, performance is based on an individual initiatives and achievements (Duanmu and Geppert, 2009) and in collectivistic cultures, employee performance is higher when placed in work groups (Hoecklin, 1995). Awareness of the cultural clues is crucial to avoid cultural difficulties when dealing with different cultural frames of reference. Previous studies have empirically examined and shown managers from individualistic cultures have different marketing strategies in comparison to those from collectivistic ones (Acar et al., 2011). Chinta and Capar (2007) found that American managers were more individualist than their Chinese counterparts while many research findings confirm that the Chinese are collectivist (Liu, 2014). Group orientation, family and kinship groups, respect of 
elders, the avoidance of conflict, and the need for harmony are considered as significant values in Chinese culture where they show higher scores for social needs (Redding, 1980). Confucianism has been seen as the philosophical foundation for collectivism. Confucian values promote the collective welfare and harmony as its ultimate goal. Confucianism discourages hedonistic and selfish desires in order to achieve moral self-discipline (Kim, 1994). Hmaida (2010), in his cross-cultural study between Morocco and France, noted a high degree of collectivism in the Moroccan sample. This finding is reinforced in study by Balambo (2014) concerning the collectivism/individualism dimension which is analyzed based on the average obtained by the variable collectivism to reveal a high score, in contrast to the individualism that denotes a low score. These results confirm previous studies on the prevalence of Hofstede collectivism in Arab countries.

Masculinity-femininity is the third dimension which measures the degree of stereotypically male traits (ambitious, assertive, and competitive) vs. the stereotypically female traits (friendly, modest, and caring) in a culture. Masculinity describes societies in which social gender roles are explicitly distinct; men are supposed to be assertive, tough, and focus on material success. Whereas "femininity" refers to the society in which gender roles overlap and both men and women are supposed to be modest and tender (Ismail and Lu, 2014). In feminine cultures, which also place a higher importance on the quality of life and psychological wellbeing, people tend to desire a career which can balance their personal and work lives. Highly masculine societies are less likely to choose personal life and career balance as they value status and achievement instead (Colakoglu and Caligiuri, 2012). Schein (2001) has found that both the United States and China show high masculinity characteristics. Morocco, like other Arab countries, also tends to be highly masculine (Hofstede, 2010). On the other hand, a strong societal cultural norm in Iran is that being of altruistic and kind to others, characteristic of a feminine culture (Dastmalchian et al., 2001).

The fourth dimension, uncertainty avoidance, defines the extent of intolerance for uncertainty and ambiguity. Societies with high uncertainty avoidance in unstructured and unpredictable situations are anxious and in low uncertainty avoidance ones, they are reflective, less aggressive, and relatively tolerant (Hofstede, 2010). In the same vein, Shuper et al. (2004) also have confirmed that countries do differently in uncertainty orientation. They found that Canada as an uncertainty orientated society copes with uncertainty by attaining clarity and finding out new information.

According to Firoz et al., (2002), there is strong loyalty to employers and employees as they hardly ever break the rules and they tend to have long-term relationships and resist change. Conversely, in low uncertainty avoidance cultures, employees are less hesitant to accept changes and they feel comfortable in unstructured environments. Therefore, there the average duration of employment is shorter (Duanmu and Geppert, 2009). According to Hofstede (2010), Morocco is classified among the countries which have a strong uncertainty avoidance tendency. In contrast, uncertainty avoidance as a cultural value is not highly emphasized in Iran (Dastmalchian et al., 2001). 


\section{Machiavellianism}

Another measure used to determine the cultural syndromes is the level of Machiavellianism. This concept was derived from Niccolo Machiavelli's The Prince (1513). According to Calhoon (1969), Machiavellian behavior refers to aggressive, manipulative, exploiting, and devious actions in order to achieve personal and organizational objectives. In order to measure the level of Machiavellianism in people, a scale, referred to as the "Mach IV Scale," was designed by Christie and Geis (1970). This scale consists of twenty statements, of which ten imply Machiavellian behavior, whereas the other ten refers to the opposite behavior. It was purposely designed that way in order to avoid response bias. Machiavellianism is an opinion about the quest to gain a competitive advantage in interpersonal competition (Walter et al., 2005) that gives one an immoral reputation for accomplishing one's own objectives (McGuire and Hutchings, 2006).

People with high Mach IV scores are said to be more likely to manipulate others, win more, and are less able to be persuaded than those scoring low on the scale. They also said to be more likely to alter the truth or act unethically in a situation where a favorable outcome is important to them (Robbins, 1999); they have a tendency to be apathetic, egoistic and malevolent in their interpersonal dealings (Paulhus and Williams, 2002). Zhang and Gowan (2012) argued that individuals with Machiavellian tendencies were less attracted to companies with high legal and ethical performances. According to Jakobwitz and Egan (2006), those with high Mach IV scores are disagreeable, dominant, narcissistic and self-interested; they have lower ethical standards and considered to be goal-oriented rather than person-oriented (Christie and Geis, 1970). On the contrary, low Mach people show cooperative tendencies and make their decisions on the basis of their internal norms more than high Machs (Czibor and Bereczkei, 2012). The former study also found that low Machs present the higher level of agreeableness and empathy (Andrew et al., 2008). Machiavellianism commonly found in western cultures and requires an individual with less trust and a greater need for security (Jaffe et al., 1989).

\section{Blake and Mouton's Conflict Management Theory}

When it comes to conflict management styles across countries, Bowlby et al. (2010) argue that a good measure would be Blake and Mouton's (1964) which theoretically specified the similarities and differences among five styles of conflict management (Table 1).

Table 1: Five Styles of Conflict Management

\begin{tabular}{cccc}
\hline Conflict Style & Definition & Objective & Behavior \\
\hline Avoidance & Withdrawal & Lose-Lose & Physically absent or silent \\
Accommodating & Acquiescence & Lose-Win & Give in; Do not "make waves" \\
Competition & Aggression & Win-Lose & Selfish, Argumentative \\
Compromise & Trade-offs & Win and Lose & "Wheeler-Dealer" \\
Collaboration & Mutual Satisfaction & Win-Win & Supportive of self and other \\
\hline
\end{tabular}

Conflicts were defined as antagonistic struggles (Coser, 1956) or breaches in normally expected behavior (Beals and Siegel, 1966). Barki and Hartwick (2004) define conflict as a dynamic process that occurs between interdependent parties as they 
experience negative emotional reactions to perceived disagreements and interference with the attainment of their goals. The conflict also has been defined as the process in which one party perceives that its interests are being thwarted/opposed or negatively affected by another party (Mukundan et al., 2013). Blake and Mouton's (1964) initial research on conflict styles has been developed based on two dimensions: degree of concern for self and for others. It includes five styles: Avoidance describes behavior that serves the minimum conflict by ignoring and is usually accompanied by withdrawal. Individuals who use this style usually fail to satisfy both their concerns and the concerns of the other(s). Accommodating is characterized by a high concern for others and a low concern for self. It emphasizes preserving the relationship with the other person rather than pursuing an individual's own concerns. Competition describes the approach that emphasizes the enforcement of one's concern for others wherein one party attempts to take control of the interactions. Compromise is a moderate concern for self and less for others. Collaboration is associated with a high concern for both parties and insured outcomes are maximized (Kim and Coleman, 2015).

Conflicts occur in the workplace due to language barriers, cultural differences, cultural prejudice, and stereotypes (Vodosek, 2007). Conflicts must be managed as they may result in low organizational performance and commitment, high turnover rates, lack of cooperation, and stress (Yaun, 2010). There are a number of researchers concerned with conflict that compares people from different countries. Most indicate that the Chinese favor more passive conflict handling styles, such as avoidance; whereas Americans prefer collaboration and competition (Knutson et al., 2000). Khanaki and Hassanzadeh (2010) surveyed Iranian students in comparison to Swedish; they found that avoidance and compromise are prevalent conflict styles among Iranian students. Verbal behavior is the main source of information for people in low context culture. Genuine and sincere confrontation is encouraged whenever a conflict occurs (Ting-Toomey, 1988). Paradoxically, indirect and ambiguous forms of communication avoid disagreement in public (Ting-Toomey, 1985). However, unarticulated messages and subjective interpretations lead to misunderstandings or confusion, resulting in conflict (Gudykunst and Nishida, 1986).

\section{Hall's High and Low Context Culture}

Finally, Hall (1976) identified a means through which we can effectively understand similarities and differences in perception and communication in different cultures. Hall's cultural context framework offers insights into one's preferred communication style, which can impact the work environment. Cultures can be placed along a highcontext/low-context continuum and no culture can be identified as exclusively HC or LC. It is crucial to define the context and shed light on differences between $\mathrm{HC}$ and LC cultures. Context has been defined as: the information that surrounds an event; it is inextricably bound up with the meaning of the event (Hall and Hall, 1989). In lowcontext countries, including North America, they insist on direct, precise, straightforward, and logical communication; whereas high-context countries (such as in Asia and the Middle East) they believe verbal communication to be only part of the overall message. The communication in these high-context cultures tends to be more indirect and more formal and places an emphasis on interpersonal relationships (Hall, 1976). The western world, specifically the United States, has a long tradition of rhetoric, a tradition that stresses the importance of the delivery of verbal messages. In 
eastern culture, the words are important, but they are inseparably from their relation to social relationships, politics, and morality (Matsumoto, 1996).

\section{Research Methodology}

This study attempts to answer the research question: How different are Americans, Canadian, Chinese, Iranians, and Moroccans when it comes to work-related values? The SSARP database provides the opportunity to investigate to what extent each country is related to, and/or differ from, the other four nationalities.

The Student $\underline{\text { Self-Assessment }}$ Research Project (SSARP) five-part questionnaire developed by Bowlby et al. (2010) was used in this research. As reported by Bowlby et al. (2010), all five questionnaires are drawn from research instruments that have "stood the test of time," and have been revised only in minor ways to ensure that English, Mandarin, and French copies all express the same messages. The SSARP White Paper sample includes 963 university students from Bowlby's research (China, Canada, and the U.S.), 234 university students from Morocco, and 300 university students from Iran. Of these students, 95\% are majoring in Business or Economics while less than $5 \%$ of the participants were majoring in Social Sciences. Respondents are equally divided among male (49\%) and female (51\%), and their median age is 21 . Bachelor's students were randomly selected, though mainly they were sophomore and junior students from both public and private schools ${ }^{1}$. Respondents were also asked about their gender, age, the number of siblings, and countries they have visited.

The questionnaire's reliability was found to be high with a Cronbach's Alpha value of 0.8093. It consists of an Ethical Standards letter as well as a permission form. Respondents were requested to fill out a demographic profile first, followed by the five surveys. R1 (the first survey) is comprised of twelve YES or NO questions; R2 (the second survey) contains sixteen questions using a scale from 0 to 100, indicating the level of importance of each statement; R3 uses the Likert Scale from 1 to 5 to respond to ten questions, indicating the level of agreement with each statement (disagree to a great extent, disagree a little, neutral, agree on a little, and agree to a great extent); R4 uses the Likert Scale, from 1 to 4, to answer fifteen questions (very unlikely, unlikely, likely, and very likely); and finally, R5 also consists of the Likert Scale from 1 to 5 (almost never, sometimes, almost always) to reply to twenty questions.

\section{Results}

\section{Theory X/Y}

In the first part of the questionnaire, students were presented with a set of twelve questions and were asked to respond either YES or NO. Half of those questions pertain to Theory $\mathrm{X}$ and the other half pertains to Theory $\mathrm{Y}$. This was coded by assigning one point to every YES and 0 points to every NO. The respondents' answers were added and the mean was calculated.

\footnotetext{
1 The primary difference between private and public schools is their source of funding. Private schools usually charge tuition and do not receive government funding.
} 
Table 2: Theory X/Y Mean Score ( $\mathrm{n}=1416)$

\begin{tabular}{cccccc}
\hline TheoryX/Y & American & Canadian & Chinese & Iranian & Moroccan \\
\hline Theory X & 3.95 & 3.73 & 3.20 & 3.81 & 3.48 \\
Theory Y & 4.19 & 4.05 & 4.02 & 3.90 & 4.05 \\
\hline
\end{tabular}

Note: American, Canadian, and Chinese mean scores from Bowlby et al. (2010).

Overall, as we can see, Theory Y scores were higher than Theory X among all groups. Looking at Theory $\mathrm{X}$ scores alone, Americans seem to have the greatest tendencies towards this management style, followed by Iranian, Canadians, Moroccans and finally the Chinese. When looking at Theory Y scores, we can see that Americans score the highest, while Canadian and Moroccan scores are very close, followed by the Chinese and finally Iranian.

\section{Personal Values}

In the second part of the questionnaire, respondents were asked to rate sixteen values, on a scale of 0-100 (indicating the level of importance). Two statements were asked for each of the eight values, the sum of the responses for each personal value was calculated, and the mean of those sums was also calculated.For example, the value Financial is measured by Q2: "a job with high salary," and is scored on a 0 to 100 scale and Q10: "Good car, clothes, house, etc." also is scored on a 0 to 100 scale. The mean values for each personal value per country are reported as below.

Table 3: Personal Value Mean Score ( $n=1497)$

\begin{tabular}{cccccc}
\hline Values & American & Canadian & Chinese & Iranian & Moroccan \\
\hline Professional & 166.1 & 168.8 & 164.1 & 158.4 & 170.9 \\
Financial & 156.3 & 159.2 & 151.9 & 167.2 & 164.3 \\
Family & $\mathbf{1 8 0 . 8}$ & $\mathbf{1 7 9 . 1}$ & $\mathbf{1 7 5 . 1}$ & $\mathbf{1 7 2 . 9}$ & $\mathbf{1 7 6 . 2}$ \\
Social & 167.1 & 167.2 & 162.4 & 152.2 & 152.8 \\
Community & 123.2 & 119.5 & 126.9 & 136.0 & 134.8 \\
Spiritual & 113.1 & 97.4 & 99.8 & 137.5 & 168.2 \\
Physical & 147.1 & 149.5 & 142.5 & 140.0 & 153.8 \\
Intellectual & 147.8 & 152.4 & 151.2 & 148.1 & 156.9 \\
\hline
\end{tabular}

Note: The values in "Bold" are the highest, and the values in "Italic" are the lowest. American, Canadian, and Chinese mean scores from Bowlby et al. (2010).

Table 3 includes the mean scores for each personal value across all five countries. Ttests, two-sample assuming unequal variances, showed that professional value for Iran is lower than professional value for Morocco $((\mathrm{M}=170.9, \mathrm{SD}=24.12)$ versus $(\mathrm{M}=158.4, \mathrm{SD}=29.0)$ conditions; $\mathrm{t}(580)=-4.75, \mathrm{p}=2.4 .10-6$. A similar test was conducted and we found that Financial value for Morocco is lower than Financial value for Iranian and that Physical, Intellectual, Spiritual, Family, Community, and Social values for Iran are lower than Physical, Intellectual, Spiritual, Family, Community, and Social values respectively for Morocco. We note that "Family" received the highest score from all groups by significant margins, followed by "Professional," whereas the second most important value for Americans is "Social" and for Iranians is "Financial." Given the Iranian respondents suffering sanctions during the study period - and youth unemployment as Iran's most significant socioeconomic issues - the results seem rational. We also note the overall low scores 
assigned to "Community" and "Spirituality" compared to the other six values, whereas this value ranks third in importance among Moroccans. Meanwhile "Community" is the least important value for Iranians. The most remarkable gap between results is the low score for "Spirituality." According to Bowlby et al. (2010), the Canadian respondents attended a Catholic university college where, during the study period, $39 \%$ of the students came from the Catholic school system. Their responses to the two questions that comprise the Spirituality score were 50.0 for " $M y$ religious belief" and 47.4 for "Meditation, reflection, praying, etc." As a comparison, Moroccans were 89.1 and 71.3 respectively. However, any opinions on the results need further research.

\section{Machiavellianism}

In the third part of the questionnaire, the Mach IV Scale was used to assess the level of Machiavellianism. Students were asked to answer ten questions on a scale of 1 to 5 , matching the extent to which they agree or disagree with the statement. Thus, the lowest and highest score are 10 and 50, the higher the number is, the greater the tendencies toward Mach. The statements were worded in a manner that required the scores for one-half to be inverted and then added to the scores of the other five statements. The responses were added together and the mean was calculated.

Table 4: Mach Mean Score ( $\mathrm{n}=1367)$

\begin{tabular}{cccccc}
\hline Mach Results & American & Canadian & Chinese & Iranian & Moroccan \\
\hline Mach Mean & 25.1 & 25.9 & 27.5 & 27.2 & 29.7 \\
\hline
\end{tabular}

Note: American, Canadian, and Chinese mean scores from Bowlby et al. (2010).

Table 4 shows cases the mean scores of the Mach IV Scale for the business students of the five countries. Bowlby et al. (2010) reported a significant difference in values between American, Canadian, and Chinese students. In particular, we found a significant difference in the scores for the Mach value for Iranian Students (M=27.2, $\mathrm{SD}=4.7)$ and Mach value for Moroccan students $(\mathrm{M}=29.7, \mathrm{SD}=4.6)$ conditions; $\mathrm{t}(603)=1.64, \mathrm{p}=0.05$. A similar test shows that the Moroccan students' average significantly exceeds all the others, with a Mach score of 29.7, followed by the Chinese (27.5).

This shows Moroccans have greater tendencies towards Machiavellianism than the other countries. As mentioned by Ali and Wahabi (1995), one of the dominant work values among Moroccan managers is the quality of being "egocentric." Our findings are relatively similar to Ali and Wahabi (1995). Generally speaking, individuals who score high on the Mach IV Scale tended to distrust others because they manipulate others and show egocentric, aggressive, and selfish characteristics (Marshall et al., 2013).

The World Value Survey (Medrano, 2015) maps interpersonal trust by asking: "Do you think that most people can be trusted?" and by compiling an internationally comparable trust index defined as:

\footnotetext{
TRUST INDEX $=100+(\%$ Most people can be trusted $)-(\%$ Can't be too careful)
} 
As of 2011, the trust indexes of the U.S. and Morocco are 70.5 and 26.2, respectively. Canada's trust index is 85.9 (as of 2005), China's trust index is 125.1 (as of 2012) and Iran's trust index is 21.8 (as of 2005). These results indicate that people in North America, Iran and Morocco are less trustworthy than China, which contradicts our findings, since both Morocco and China ranked higher than others on the Mach IV Scale, and, as we mentioned before, people and cultures with high Mach IV scores are less trustworthy than those with low Mach IV scores.

\section{Conflict Management Styles}

The fourth part of the questionnaire comprises fifteen statements on a scale of 1 to 4 according to the likelihood they behave in a conflict situation. Each of the conflict style listed in table 5 was represented by three randomly statements, thus the lowest and highest possible scores are 3 and 12, respectively. Once again, we calculated the sum of each respondent's answers and we found the mean for each of the five styles.

Table 5: Conflic Styles Mean Score ( $\mathrm{n}=1458)$

\begin{tabular}{cccccc}
\hline Style & American & Canadian & Chinese & Iranian & Moroccan \\
\hline Avoidance & 8.8 & 8.8 & 9.0 & 9.3 & 9.2 \\
Accommodating & 9.5 & 9.7 & $\mathbf{1 0 . 1}$ & $\mathbf{9 . 7}$ & $\mathbf{9 . 6}$ \\
Competition & $\mathbf{1 0 . 1}$ & $\mathbf{1 0 . 0}$ & 9.8 & 9.05 & $\mathbf{9 . 6}$ \\
Compromise & 8.6 & 8.5 & 9.3 & 8.2 & 8.7 \\
Collaboration & 8.7 & 8.7 & 8.5 & 8.9 & 9.2 \\
\hline
\end{tabular}

Note: The values in "Bold" are the highest, and the values in "Italic" are the lowest. China, Canada and America from Bowlby et al. (2010).

Table 5 shows the mean scores for each one of the five conflict management styles. "Competition" scores were significantly highest among all groups, except Iranians, followed by Moroccans. In particular, competing for Iran is lower than for Morocco $(9.05,1.61)$ vs $(9.6,1.54) ; \mathrm{t}(602)=1.64, \mathrm{p}=2.3810-5$. Similar $\mathrm{t}$-test showed that "Collaboration," "Avoidance," and "Accommodating" for Morocco is lower than "Collaboration," "Avoidance," and "Accommodating" for Iran. Overall the Chinese scored significantly higher in "Accommodating." The second most preferred conflict management style is "Accommodating" among the five groups, while "Competition" ranked second among the Chinese. The least favorite style for Moroccans, Americans, Canadians and Iranians is "Compromise," and for the Chinese it is "Collaboration."

\section{Cultural Context}

The final part attempts to evaluate whether the majority of the respondents fall in the High Context culture or the Low Context culture categories. A total of twenty statements were included, ten relating to each category. The students were requested to score from 1 to 5 (to a maximum score of 50). The sum of each score for the respondents and the mean score were calculated 
Table 6: HC/LC Mean Score ( $\mathrm{n}=1497)$

\begin{tabular}{cccccc}
\hline HC/LC & American & Canadian & Chinese & Iranian & Moroccan \\
\hline High Context & 31.0 & 32.2 & 33.4 & 33.7 & 34.5 \\
Low Context & 33.1 & 34.6 & 33.2 & 34.1 & 35.5 \\
\hline
\end{tabular}

Note: American, Canadian and Chinese mean scores from Bowlby et al. (2010).

Table 6 shows the mean scores for the two types of context cultures. Chinese respondents scored higher on HC communication; conversely American, Canadian, Iranian, and Moroccan strongly lean towards Low Context communication. It is interesting to note that Moroccans score higher than other countries on HC while the result shows Moroccans are disposed towards Low Context communication, which appears inconsistent with the literature on this subject.

\section{Discussion and Conclusion}

This paper represents a valuable guide to managers by offering a greater understanding of youth culture as the future generation of work resource. The SSARP enabled us to evaluate business students from five different nationalities. Table 7 recapitulates the main findings of the study.

Table 7: Summary of Key Findings for Five Different Nationalities Business Students

\begin{tabular}{|c|c|c|c|c|c|}
\hline & American & Canadian & Chinese & Iranian & Moroccan \\
\hline Theory X/Y & Theory Y & Theory Y & Theory Y & Theory Y & Theory Y \\
\hline $\begin{array}{c}\text { Personal } \\
\text { Values }\end{array}$ & $\begin{array}{c}\text { Family } \\
\text { Social } \\
\text { Professional }\end{array}$ & $\begin{array}{c}\text { Family } \\
\text { Professional } \\
\text { Social }\end{array}$ & $\begin{array}{c}\text { Family } \\
\text { Professional } \\
\text { Social }\end{array}$ & $\begin{array}{c}\text { Family } \\
\text { Financial } \\
\text { Professional }\end{array}$ & $\begin{array}{c}\text { Family } \\
\text { Professional } \\
\text { Spiritual }\end{array}$ \\
\hline Mach. & 5 & 4 & 2 & 3 & 1 \\
\hline $\begin{array}{c}\text { Conflict }^{2} \\
\text { Styles }\end{array}$ & $\begin{array}{l}\text { Competition + } \\
\text { Accommodating } \\
+ \text { Compromise - }\end{array}$ & $\begin{array}{c}\text { Competition + } \\
\text { Accommodating } \\
+ \text { Compromise } \\
-\end{array}$ & $\begin{array}{l}\text { Accommodating } \\
+ \text { Competition + } \\
\text { Collaboration - }\end{array}$ & $\begin{array}{c}\text { Accommodating } \\
+ \text { Avoidance + } \\
\text { Competition - }\end{array}$ & $\begin{array}{l}\text { Competition + } \\
\text { Accommodating } \\
+ \text { Compromise - }\end{array}$ \\
\hline $\begin{array}{l}\text { Cultural } \\
\text { Context }\end{array}$ & $\mathrm{LC}$ & $\mathrm{LC}$ & $\mathrm{HC}$ & $\mathrm{LC}$ & $\mathrm{LC}$ \\
\hline
\end{tabular}

Note: American, Canadian and Chinese mean scores from Bowlby et al. (2010).

The results show that Theory $\mathrm{Y}$ is prevalent among all our sample nations (Morocco, America, Canada, China, and Iran). The family is the core value across all nationalities, followed by Professional in Morocco, Canada, and China; Social in the U.S.; and Financial in Iran. The findings support the claim that traditional Confucian values remain important to young Chinese attitudes (Lan et al., 2009). The prolonging of the recession and the sanctions have hurt Iran's youth, resulting in unemployment and this causes concern (Salehi-Isfahani, 2010). Spirituality scores amongst Moroccans were much higher than reported in other countries. This result could imply that religious or spiritual factors may play a role in mitigating the higher

\footnotetext{
2. Morocco Accomodation and Competition are the top values so they get $\mathrm{a}+$ and Compromise the lesser value it is noted -. And so on.
} 
Machiavellian scores. Miesing and Preble (1985) tested Mach self-assessment among 487 MBA students. They found that women compared to men and those with more religious conviction reported lower levels of Mach. The result is in contrast to our finding of Moroccans. Although their spirituality value is higher than others, Moroccans reported the highest Mach IV scores, signaling more pragmatism and emotional distance. This result suggests that foreign employers must understand that the Moroccans view of workplace responsibility may require a greater synthesis with their personal goals.

Moroccan culture is considered to be collectivist (Hofstede, 2009); however, our sample respondents had the lowest scores in Community, which might suggest a trend towards individualistic that is more commonly found in Western cultures. In individualistic cultures people are expecting to stand up for themselves and their immediate family and they are focused on individual rights and achievements. Management of an individual's link to their performance and the task is more important than personal relationships (Hofsted, 2007). Thus, young Moroccans might cope better working independently and respond better to individual incentives than their predecessors. The case of Morocco is particularly interesting as the difference in value recorded (highest values: Completion, Accommodating) might be understood from Morocco's colonial past. In Morocco, the French colonial power had installed obligatory education. Yet, admittance was regulated and only the native elites were allowed in. The French made sure that the education system would not allow schools to empower the people of Morocco to destabilize the authority; consequently, the education system focused on training an elite that bolstered the French administration and weakened any autonomist ambition. Hence "Competition" and "Accommodating" values were promoted (Akkari, 2004). Post-colonial education continued to be an advantage for social promotion and up till now Moroccan families compete to register their offspring in French schools (Ennaji, 2005). Chinese typically believe that it is acceptable to treat people differently depending on their relationship, whereas Americans believe it is fair to treat everyone the same based on a set of principles and rules (Trompenaars and Hampden-Turner, 2012). Besides, the Confucian value of harmony is reflected in the style of "Accommodating," which Bowlby's findings (2011) support.

Although the Cultural Context scores were close, the score for Low Context was greater. Given a holistic approach to communication, the results show that its purpose in Chinese culture as High Context is not to enhance speakers individually through the articulation of words, but rather to promote harmony and social integration - whereas Low Context cultures place a great deal of power in words. Thus, foreign managers might comfortably opt for a communication style that is more straightforward, logical direct, and precise. Moreover, if we look at the conflict management styles of Low Context students (United States, Canada, China, and Morocco) and High-Context culture students (Iranian), the five styles follow an almost same pattern of the overall results. Competition is the most popular style with both Western and Eastern culture students. Similarly, "Compromise" is the least preferred styles by both groups. Although the initial response in a variety of conflict situation may be interpreted as a tendency to discuss the matter, our findings show collaboration doesn't seem to work as the most preferred style and may use the next after "Competition" and "Accommodating." 


\section{Further Research Directions}

The findings of this research show that, although over these century countries have pushed ever further into global commerce and that citizens are exposed to a tremendous variety of products and ideas from all over the world, values inculcated by different educations systems are still thriving. Modern management methods are built on a strong sense community, innovation, and self-esteem (Cropley and Cropley, 2014). Yes, too often students continue to be taught values that are antithetical to the values on which modern business and entrepreneurial spirit can develop. Moroccan business students, for example, seems to be elitist, have little inclination for community spirit, value security in life, and are more inclined to have Machiavelli management style. Since cultural values are at the heart of a nation economic development (Lipset, 2000) it seems essential for future research to focus on education systems and how values are passed on to the future generation. The goal would indeed be not to propose a standardized educational system, but promote specific values beneficial to the transformation of society for the better for all.

\section{References}

Acar, A., Premasara, J. M., and Glen, J.S. (2011), "An Exploratory Study about Culture and Marketing Strategy", Asian Journal of Business Research, vol. 1, no .1, pp. 48-61.

Albaum, G., Yu, J., Wiese, N., Herche, J., Evangelista, F., and Murphy, B., (2010), "Culturebased values and management style of marketing decision makers in six Western Pacific Rim countries", Journal of Global Marketing, vol. 23, no .2, pp. 139-151.

Akkari, A., (2004), "Education in the Middle East and North Africa: The current situation and future challenges", International Education Journal, vol. 5, no .2, pp. 144-153.

Ali, A., (1988), "A cross-national perspective of managerial work value systems", Advances in international comparative management, vol. 3, no. 15, pp. 1-169.

Ali, A. J., and Wahabi, R., (1995), "Managerial value systems in Morocco", International Studies of Management and Organization, vol. 25, no. 3, pp. 87-96.

Karin Andreassi, J., Lawter, L., Brockerhoff, M., and J. Rutigliano, P., (2014), "Cultural impact of human resource practices on job satisfaction: A global study across 48 countries", Cross cultural management, vol. 21, no. 1, pp. 55-77.

Andrew, J., Cooke, M., and Muncer, S. J. (2008), "The relationship between empathy and Machiavellianism: An alternative to empathizing-systemizing theory", Personality and Individual Differences, vol. 44, no. 5, pp. 1203-1211.

Balambo, M. A., (2014), "Hofstede's model revisited: an application for measuring the Moroccan national culture", International Journal of Business Quantitative Economics and Applied Management Research, vol. 1, no. 3, pp. 5-9.

Barki, H., and Hartwick, J., (2004), "Conceptualizing the construct of interpersonal conflict", International journal of conflict management, vol. 15, no. 3, pp. 216-244.

Beals, A. R., and Siegel, B. J., (1966), Divisiveness and social conflict: An anthropological approach. Stanford University Press.

Blake, R.R. and Mouton, J.S. (1964), The Managerial Grid: Key Orientations for Achieving Production through People, Gulf Publishing, Houston, TX.

Bowlby, K., Cope, T., Hill, T., Li, L., McDermott, E. P., Obar, R. and Popham, D. (2010). A sino-Western comparison of work-related values by citizenship, based on selfassessment from American, Chinese and Canadian students. A White Paper presented to The International Academy of Business and Public Administration Disciplines, 7( $3)$. 
Bowlby, K., McDermott, E. P., and Obar, R., (2011), "Personal values, behavior and conflict resolution styles: A study of contemporary mainland Chinese business students", Journal of International Business Ethics, vol. 4, no. 1, p. 42.

Bradshaw, R., Chebbi, M., and Oztel, H., (2015), "Leadership and knowledge sharing", Asian Journal of Business Research ISSN, 1178(8933).

Brocaglia, J. (2011). The importance of human capital. Alta Associates, 1-4.

Calhoon, R. P., (1969), "Niccolo Machiavelli and the Twentieth Century Administrator", Academy of Management Journal, vol. 12, no. 2, pp. 205-212.

Chinta, R., and Capar, N., (2007), "Comparative analysis of managerial values in the USA and China", Journal of Technology Management in China, vol. 2, no. 3, pp. 212-224.

Christie, R., and Geis, F. L. (1970). Studies in Machiavellianism. New York: Academic Press.

Clugston, M., Howell, J. P., and Dorfman, P. W., (2000), "Does cultural socialization predict multiple bases and foci of commitment?", Journal of management, vol. 26, no. 1, pp. 5-30.

Colakoglu, S., and Caligiuri, P., (2012), "Cultural influences on Millennial MBA students' career goals: Evidence from 23 countries", Managing the new workforce: International perspectives on the millennial generation, pp. 262-280.

Cropley, D. H., and Cropley, A. J., (2014), "Managing entrepreneurship for innovation: a psychological analysis", (Doctoral dissertation, Edward Elgar Publishing Limited).

Coser, L. A. (1956). The functions of social conflict (Vol. 9). Routledge.

Czibor, A., and Bereczkei, T., (2012). "Machiavellian people's success results from monitoring their partners", Personality and Individual Differences, vol. 53, no. 3, pp. 202-206.

Dastmalchian, A., Javidan, M., and Alam, K., (2001), "Effective leadership and culture in Iran: An empirical study", Applied Psychology, vol. 50, no. 4, pp. 532-558.

Duanmu, J. and Geppert, M. (2009), International Business management (2nd Ed.) Irwin: McGraw-Hill.

Ennaji, M. (2005), Multilingualism, cultural identity, and education in Morocco. Springer Science and Business Media.

Firoz, N. M., Maghrabi, A. S., and Hee Kim, K., (2002), "Think globally manage culturally", International Journal of Commerce and Management, vol. 12, no. 3/4, pp. 32-50.

Flowers, V.S., Hughes, C.L., Myers, M., and Myers, S., (1975), Managerial values for working: An AMA survey report. New York: ANACOM.

Flowers, V. S., and Hughes, C. L., (1978), "Choosing a leadership style", Personnel, vol. 55, no. 1 , pp. 48-59.

Gudykunst, W. B., and Nishida, T, (1986), "Attributional confidence in low-and high-context cultures", Human communication research, vol. 12, no. 4, pp. 525-549

Hall Edward, T. (1976), Beyond culture. NewYork. Doubleday.

Hall, E. T., and Hall, M. R, (1989), Understanding cultural differences. Intercultural press.

Hmaida J, (2010), "L'impact de la conception de soi sur la catégorisation des marques", Congrés AFM, Le Mans.

Hoecklin, L. A., (1995), Managing cultural differences: Strategies for competitive advantage. Addison-Wesley Longman Limited.

Hofstede, G. J., (2009), "Research on cultures: how to use it in training?", European Journal of Cross-Cultural Competence and Management, vol. 1, no. 1, pp. 14-21.

Hofstede. G, Hofstede .G, Minkov.M, Cultures and Orgabisations :Software of The Mind. (2010) (Rev. and Extended 3 rd ed.) New York, McGraw-Hill

Hughes, C. L., and Flowers, V. S. (1978). Value systems analysis: Theory and management application. Center for Values Research.

Husted, B. W., and Allen, D. B., (2008), "Toward a model of cross-cultural business ethics: The impact of individualism and collectivism on the ethical decision-making process", Journal of Business Ethics, vol. 82, no. 2, pp. 293-305. 
Ike. Nnia, Mba, Sr., (2015), " Conflicts Encourntered by Multinational Corporations in CrossCultural Communication and its Solutions", Journal of International Business and Economics, vol. 3, no. 1, pp. 86-92.

Ismail, M., and Lu, H. S., (2014), "Cultural values and career goals of the millennial generation: An integrated conceptual framework", Journal of International Management Studies, vol. 9, no. 1, pp. 38-49.

Jaffe, E. D., Nebenzahl, I. D., and Gotesdyner, H., (1989), "Machiavellianism, task orientation and team effectiveness revisited", Psychological Reports, vol. 64, no. 3, pp. 819-824.

Jakobwitz, S., and Egan, V., (2006), "The dark triad and normal personality traits", Personality and Individual Differences, vol. 40, no. 2, pp. 331-339.

Khanaki, H., and Hassanzadeh, N., (2010), "Conflict management styles: The Iranian general preference compared to the Swedish", International Journal of Innovation, Management and Technology, vol. 1, no. 4, p. 419.

Kim, U. (1994), "Individualism and collectivism: Conceptual clarification and elaboration", Cross Cultural Research and Methodology Series-Sage-, vol. 18, no. 1, pp. 19-19.

Kim, R., and Coleman, P. T., (2015), "The Combined Effect of Individualism-Collectivism on Conflict Styles and Satisfaction: An Analysis at the Individual Level", Peace and Conflict Studies, vol. 22, no. 2, pp. 137-159.

Knutson, T. J., Hwang, J. C., and Deng, B. C., (2000), "Perception and management of conflict: A comparison of Taiwanese and US business employees", Intercultural Communication Studies, vol. 9, no. 2, pp. 1-32.

Lan, G., Ma, Z., Cao, J., and Zhang, H., (2009), "A comparison of personal values of Chinese accounting practitioners and students", Journal of Business Ethics, vol. 88, pp. 59-76.

Lerner, A., (2011), "McGregor's legacy: thoughts on what he left, what transpired, and what remains to pursue", Journal of Management History, vol. 17, no. 2, pp. 217-237.

Lipset, S. M., (2000), Values and entrepreneurship in the Americas, pp. 110-128.

Liu, C., (2014), "Chinese, Why Don't You Show Your Anger?--A Comparative Study between Chinese and Americans in Expressing Anger", International Journal of Social Science and Humanity, vol. 4, no. 3, p. 206.

Lulofs, R. S., and Cahn, D. D., (2000), Conflict: From theory to action. Allyn and Bacon.

Machiavelli, N. (1993), The Prince (1513). Hertfordshire: Wordsworth Editions.

Marshall, A., Baden, D., and Guidi, M., (2013), "Can an ethical revival of prudence within prudential regulation tackle corporate psychopathy?", Journal of Business Ethics, vol. 117 , no. 3, pp. 559-568.

Matsumoto, D. (1996), Culture and Psychology. Pacific Grove, CA: Brooks/Cole Publishing Company.

McGregor, D., (1960), Theory X and theory Y. Organization theory, pp. 358-374.

McGuire, D., and Hutchings, K., (2006), "A Machiavellian analysis of organisational change", Journal of Organizational Change Management, vol. 19, no. 2, pp. 192-209.

Medrano, Jaime Díez (2015), "Interepersonal trust," World Values Survey website.

Miesing, P., and Preble, J. F., (1985), "A comparison of five business philosophies", Journal of Business Ethics, vol. 4, no. 6, pp. 465-476.

Mukundan, S., Dhanya, M., and Saraswathyamma, K. P., (2013), "A study on the conflict resolution styles of generation Y students in Indian context", International Journal of Global Business, vol. 6, no. 1, p.81.

Nouiga, M., (2003), La conduite du changement par la qualité dans un contexte socioculturel. Essai de modélisation systémique et application à l'entreprise marocaine (Doctoral dissertation, Arts et Métiers ParisTech).

Papa, M. J., Daniels, T. D., and Spiker, B. K., (2007), Organizational communication: Perspectives and trends. Sage.

Paulhus, D. L., and Williams, K. M., (2002), "The dark triad of personality: Narcissism, Machiavellianism, and psychopathy", Journal of research in personality, vol. 36, no. 6, pp. 556-563. 
Redding, S. G., (1980), "Cognition as an aspect of culture and its relation to management processes: An exploratory view of the Chinese case", Journal of Management Studies, vol. 17, no. 2, pp. 127-148.

Robbins, S. P. (Ed.). (1999). The Prentice Hall Self-assessment Library. Prentice Hall.

Sackmann, S. A., \& Phillips, M. E., (2004), "Contextual influences on culture research: Shifting assumptions for new workplace realities", International Journal of Cross Cultural Management, vol. 4, no. 3, pp. 370-390.

Salehi-Isfahani, D. (2010). 'Iran's youth, the unintended victims of sanctions,'. Dubai Initiative-Policy Brief, Cambridge, MA: The Dubai Initiative, Belfer Center for Science and International Affairs, John F. Kennedy School of Government, Harvard University,

Schein, V. E., (2001), "A global look at psychological barriers to women's progress in management", Journal of Social issues, vol. 57, no. 4, pp. 675-688.

Schwartz, S. H., \& Bardi, A., (2001), "Value hierarchies across cultures: Taking a similarities perspective", Journal of cross-cultural psychology, vol. 32, no. 3, pp. 268-290.

Shenkar, O., (2001), "Cultural distance revisited: Towards a more rigorous conceptualization and measurement of cultural differences", Journal of international business studies, vol. 32, no. 3, pp. 519-535.

Shuper, P. A., Sorrentino, R. M., Otsubo, Y., Hodson, G., and Walker, A. M, (2004), "A theory of uncertainty orientation: Implications for the study of individual differences within and across cultures", Journal of Cross-Cultural Psychology, vol. 35, no. 4, pp. 460-480.

Ting-Toomey, S. (1985). Toward a theory of conflict and culture. In W. Gudykunst, L. Stewart, and S. Ting-Toomey (Eds.), Communication, culture, and organizational processes (pp. 71-86). Beverly Hills, CA: Sage.

Ting-Toomey, S. (1988). Intercultural conflict styles: A face-negotiation theory. In Y. Kim and W. Gudykunst (Eds.), Theories in intercultural communication (pp. 213-35). Newbury Park, CA: Sage

Triandis, H. C., (1996), "The psychological measurement of cultural syndromes", American psychologist, vol. 51, no. 4, p.407.

Trompenaars, F., and Hampden-Turner, C. (2012). Riding The waves of culture. New York, NY: McGraw-Hill.

Urban, G. L., (2003), The trust imperative.

Vodosek, M., (2007), "Intragroup conflict as a mediator between cultural diversity and work group outcomes", International Journal of Conflict Management, vol. 18, no. 4, pp. 345-375.

Walter, H. L., Anderson, C. M., and Martin, M. M., (2005), "How subordinates' Machiavellianism and motives relate to satisfaction with superiors", Communication Quarterly, vol. 53, no. 1, pp. 57-70.

Weatherly, L. A., (2003), "Human capital--the elusive asset", HR Magazine, vol. 48, no. 3, pp.1.

Wolburg, J. M., and Pokrywczynski, J., (2001), "A psychographic analysis of Generation Y college students", Journal of advertising research, vol. 41, no. 5, pp. 33-52.

Yuan, W, (2010), "Conflict management among American and Chinese employees in multinational organizations in China", Cross Cultural Management: An International Journal, vol. 17, no. 3, pp. 299-311.

Zhang, L., and Gowan, M. A., (2012), "Corporate social responsibility, applicants' individual traits, and organizational attraction: A person-organization fit perspective", Journal of Business and Psychology, vol. 27, no. 3, pp. 345-362. 